\title{
Nanocarriers as Promising Novel Systems for Controlled Delivery of Diclofenac Sodium
}

\author{
Gannu Praveen Kumar, ${ }^{1, *}$ Pogaku Rajeshwar Rao ${ }^{2}$ \\ ${ }^{1}$ Department of Pharmaceutics, Sahasra Institute of Pharmaceutical Sciences, India \\ ${ }^{2}$ Apotex Pharmaceuticals Limited, India
}

Copyright (C) 2015 Horizon Research Publishing All rights reserved.

\begin{abstract}
The formulation and evaluation of diclofenac sodium from liposomes, niosomes and nanoemulsion are analyzed. The release profiles of diclofenac sodium were almost similar in all the formulations. It is found that $85 \%$ of diclofenac sodium diffused out from the colloidal systems within $8 \mathrm{hrs}$ and practically all the drug was released within $12 \mathrm{hrs}$. In addition to this controlled release, the similarity of the release profiles obtained for liposomes, niosomes and nanoemulsion signifies that the internal structure has little role in the release process. The drug released fast and completely from the carriers upon high dilution, but it is slowed down a little when they are not diluted. The maximium amount of diclofenac sodium was released from nano emulsion as well as liposomes after $12 \mathrm{hrs}$ at 1 in 200 dilution where as in niosomes, it was found at 1 in 100 dilution. But surprisingly, the release was decreased upon further dilution. The higher the surfactant content, the higher the globule size of the nanoemulsion. The mean size of the systems was decreased upon increasing dilution. Among all the systems, the mean size of niosomes was decreased upon increasing the dilution up to 1:200. It was finally depicted that the dilution effect on the zeta potential of the systems shifted from negative to positive by adding polysorbate 80 . The zeta potential of all the systems was significantly good indicating stable systems.
\end{abstract}

Keywords Liposomes, Nanoemulsion, Niosomes, Release Studies, Zeta-potential

\section{Introduction}

Of the various nanosystems available, synthetic carriers such as liposomes have been used extensively ${ }^{1,2}$. Liposomes are biodegradable, nontoxic, uni or multilamellar vesicles, formed from naturally occurring phospholipids which have the ability to entrap and retain a wide range of drugs either in the aqueous or lipid phase ${ }^{3-6}$. Liposomes can be administered by oral $^{7}$, parenteral and transdermal routes ${ }^{8,9}$. Their pharmacokinetic properties depend upon their size, surface charge, lipid composition, fluidity of the membrane, dose and route of administration ${ }^{10-11}$. When administered intravenously, the multilamellar (MLV) liposomes have an elimination half life of 30 to 120 minutes, whereas small unilamellar (SUV) liposomes are eliminated exponentially with a half life of 80 minutes to 2 days. In the liver, irrespective of surface charge, MLV liposomes are predominantly internalized by kupffer cells, while cationic SUV liposomes are taken up by the hepatocytes, neutral and anionic SUV liposomes are distributed equally between kupffer cells and hepatocytes. Niosomes have been largely proposed as drug delivery systems ${ }^{12}$. This class of vesicles appear are similar in terms of their physical properties to liposomes, being prepared in the same way and under a variety of conditions, forming unilamellar or multilamellar structures $^{13}$. They may be regarded either as inexpensive alternatives of non-biological origin to liposomes. Particularly, these vesicles were introduced in reason of the higher chemical stability of the nonionic surfactants compared to that of phospholipids. Phospholipids are in fact subjected to stability problems due to the easy hydrolysis of esters bonds or to the possible peroxidation of unsaturated bonds. Moreover, another disadvantage related to the nature of liposomes is referred to the unreliable reproducibility. This series of problems in the use of liposomes as drug carriers thought provoked the researchers the utilization of alternative sources to make vesicles and among them the use of non-ionic surfactants. An increasing number of non-ionic surfactants have been found to form vesicles able to entrap hydrophobic and hydrophilic solutes. Particularly, niosomes are prepared from glucosyl dialkyl ethers ${ }^{14}$, crown ethers, spans $^{15}$ and polyoxyethylene alkyl ethers ${ }^{16}$. Nanoemulsion ${ }^{17}$ is preferred because of nanoscale size range of the dispersed droplets with a mean droplet size of about $250 \mathrm{~nm}$. The physical stability of nanoemulsion can substantially be improved with the help of suitable. In addition, some studies have compared the performance of different nanoemulsified systems prepared with similar oils and surfactants for applications such as controlled drug release ${ }^{18}$ and or drug incorporation for protection ${ }^{19}$. The possible usefulness of 
NEs as nanocarriers is their ability to solubilize substantial amounts of hydrophilic/hydrophobic drug either at the innermost (oil or water) phase or at the $\mathrm{o} / \mathrm{w}$ or w/o interfaces. They are biocompatible, biodegradable, physically stable, and relatively easy to produce on a large scale using proven technology ${ }^{20}$. This allows efficient delivery of therapeutic agents to target sites in the body. Nanocarriers, in their various forms, have the possibility of providing endless opportunities in the area of drug delivery and therefore are increasingly being investigated to harness their potential ${ }^{21}$. The pharmaceutical colloidal carriers such as liposomes, niosomes and nanoemulsions are normally used to control the drug release in a desirable fashion. They improve the solubility of hydrophobic and hydrophilic compounds and render them suitable for different routes of administration ${ }^{22}$. Several reports prove that most of the NSAIDS are potential candidates for delivering through nanocarriers by various routes of administration. The following Table 1.0 lists some of the NSAIDS incorporated in nanocarriers.

Diclofenac sodium (DS) is an analgesic and non-steroidal anti-inflammatory drug (NSAID). Its use is associated with fatal gastrointestinal side effects. It is documented that the solubility and bioavailability of DS has been attributed to the higher affinity of the drug molecules towards the lipids, oil and nonionic surfactants ${ }^{32,33}$. Studies have shown that nanoemulsion, liposome or noisome can enhance transmembrane passage across the digestive tract and transdermal drug permeability, thus improving the bioavailability of the guest molecules ${ }^{34-36}$. The following Table 2.0 lists various nanocarriers developed for diclofenac sodium and thus demonstrates the versatile suitability for DS.

Table 1. NSAIDS and nanocarriers

\begin{tabular}{|c|c|c|c|c|}
\hline SNO & NSAIDs & Nano carrier & Results & References \\
\hline 1 & Celecoxib & NLC & $\begin{array}{l}\text { Gel formulations of celecoxib prepared with NLC exhibited fasted } \\
\text { drug input and sustained anti-inflammatory activity up to } 24 \mathrm{~h} \text {. }\end{array}$ & $\begin{array}{l}\text { Joshi et al, } \\
2008^{23}\end{array}$ \\
\hline 2 & Flufenamic acid & $\begin{array}{l}\text { Poly(lactide-coglycolide) } \\
\text { Nanoparticles }\end{array}$ & $\begin{array}{l}\text { Nanoencapsulation of flufenamic acid has significantly increased } \\
\text { drug transport and accumulation in the skin. }\end{array}$ & $\begin{array}{l}\text { Luengo et al., } \\
2006^{24}\end{array}$ \\
\hline 3 & Flurbiprofen & NLC & $\begin{array}{l}\text { NLC formulation of flurbiprofen was led to the increase in drug } \\
\text { permeation with respect to its conventional solution. }\end{array}$ & $\begin{array}{l}\text { Gonzales-Mira } \\
\text { et al., } 2011^{25} \\
\end{array}$ \\
\hline 4 & Flurbiprofen & SLN & $\begin{array}{l}\text { SLN dispersion and gel formulation showed a sustained drug } \\
\text { release over } 24 \mathrm{~h} \text { period. }\end{array}$ & $\begin{array}{l}\text { Jain et al., } \\
2005^{26}\end{array}$ \\
\hline 5 & Indomethacin & NLC & $\begin{array}{l}\text { Prolonged in vivo anti-inflammatory activity of indomethacin was } \\
\text { observed with NLC hydrogels compared to its aqueous solution and } \\
\text { hydroalcoholic gel. }\end{array}$ & $\begin{array}{l}\text { Ricci etal., } \\
2005^{27}\end{array}$ \\
\hline 6 & Indomethacin & Nanocapsule & $\begin{array}{l}\text { Transdermal delivery of indomethacin with } \\
\text { polyn-butylcyanoacrylate nanocapsules was improved with respect } \\
\text { to conventional gel formulation. }\end{array}$ & $\begin{array}{l}\text { Miyazaki et al., } \\
2003^{28}\end{array}$ \\
\hline 7 & Ketoprofen & SLN & $\begin{array}{l}\text { Ketoprofen loaded SLN formulations showed a prologed } \\
\text { anti-inflammatory effect compared to its solution. }\end{array}$ & $\begin{array}{l}\text { Puglia et al., } \\
2008^{29}\end{array}$ \\
\hline 8 & Ketorolac & NLC & $\begin{array}{l}\text { Topical application of the ketorolac HPBCD complex resulted in } \\
\text { transdermal delivery of ketorolac whereas liposomal ketorolac } \\
\text { dispersions promoted dermal localization of the drug. }\end{array}$ & $\begin{array}{l}\text { Puglia et al., } \\
2006^{30}\end{array}$ \\
\hline 9 & Nimesulide & $\begin{array}{l}\text { Nanocapsule } \\
\text { /nanoemulsion } \\
\text { /nanospheres }\end{array}$ & $\begin{array}{l}\text { Nimesulide-loaded nanocarriers formulated in hydrophilic gels } \\
\text { exhibited good physicochemical properties for its dermal } \\
\text { administration. }\end{array}$ & $\begin{array}{l}\text { Alves et al., } \\
2005^{31}\end{array}$ \\
\hline
\end{tabular}

Table 2. Diclofenac Sodium and nanocarriers

\begin{tabular}{|c|c|c|c|}
\hline SNO & Nano carrier & Results & References \\
\hline 1 & Microemulsion & $\begin{array}{l}\text { Skin irritation study on human volunteers showed no visible reaction indicating } \\
\text { the safety as a drug carrier for topical application. }\end{array}$ & Gulten Kantarc et al., $2007^{37}$ \\
\hline 2 & $\begin{array}{l}\text { Liposomes, } \\
\text { Ethosomes and } \\
\text { Transfersomes }\end{array}$ & $\begin{array}{l}\text { Results revealed that both ethosome and transfersome formulations can act as } \\
\text { drug reservoir in skin and extend the pharmacologic effects of Diclofenac } \\
\text { sodium }\end{array}$ & $\begin{array}{l}\text { Saeed Ghanbarzadeh et al., } \\
\qquad 2013^{38}\end{array}$ \\
\hline 3 & Microemulsion & $\begin{array}{c}\text { Diclofenac permeability through Caco-2 monolayer cells increases when } \\
\text { lecithin is embedded into the interface. }\end{array}$ & $\begin{array}{l}\text { Aviram Spernath et al., } \\
2007^{39}\end{array}$ \\
\hline 4 & Microemulsion & $\begin{array}{l}\text { The transdermal fluxes were significantly higher than those obtained by } \\
\text { application of the drug in aqueous solution }\end{array}$ & $\begin{array}{l}\text { Amnon C. Sintov et al., } \\
2006^{40}\end{array}$ \\
\hline 5 & $\begin{array}{l}\text { Magnetic } \\
\text { microspheres }\end{array}$ & $\begin{array}{l}\text { Majority of injected dose was recovered from lungs, spleen and liver indicating } \\
\text { that particle size is crucial to avoid the entrapment of microspheres in non-target } \\
\text { organs. }\end{array}$ & $\begin{array}{l}\text { Muniyandy Saravanan et al., } \\
\qquad 2004^{41}\end{array}$ \\
\hline 6 & $\begin{array}{c}\text { Normal } \\
\text { microspheres }\end{array}$ & $\begin{array}{l}\text { Both in the arthritic and normal contralateral knee joints radioactivity count } \\
\text { ratios demonstrated less arthritic lesions. }\end{array}$ & M. tuncë ay et al., $2000^{42}$ \\
\hline 7 & Nanocapsules & $\begin{array}{l}\text { The percentage loading efficiency of DS was only } 50 \pm 60 \% \text { and release at } 8 \mathrm{~h} \\
\text { was only } 60 \% \text {. }\end{array}$ & A. R. kulkarni et al., $2000^{43}$ \\
\hline 8 & Micelles & $\begin{array}{l}\text { The thermodynamic parameter of standard free energy change indicates the } \\
\text { greater ease of aggregation for the surfactant system with increasing } \\
\text { concentration of Diclofenac Sodium. }\end{array}$ & S.K. Mehta et al., $2005^{44}$ \\
\hline
\end{tabular}


Therefore, the rational design of formulations takes advantage of any interactions taking place within the system. The main aim of the work is to explore the influence of nanosystems (Liposome, Niosome and Nanoemulsion) on the release characteristics and performance of DS and thereby to analyze the change in behavior of nanosystems in the presence of DS and thus to develop and compare nanoformulations as drug carriers for oral, parenteral and topical application and to demonstrate the release features of the formulations. In the present study, detailed physicochemical properties of selected nanoemulsion, liposome and niosome in the presence of DS for size, zeta potential and release studies were examined.

\section{Materials and Methods}

\subsection{Preparation of Diclofenac Sodium Nanosystems}

The composition of the tested liposomes, niosomes, and nanoemulsions formulae are reported in Table 3.0. Nanosystems containing diclofenac sodium were prepared by flash evaporation method ${ }^{45,46}$. Briefly, diclofenac sodium, surfactants, cholesterol and lipids were accurately weighed into a long necked quick fit round bottom flask and dissolved in $10 \mathrm{ml}$ dichloromethane and added to with 10 $\mathrm{ml}$ of phosphate buffered saline (PBS, $\mathrm{pH}$ 7.4). The organic solvent was slowly evaporated at $60^{\circ} \mathrm{C}$ under reduced pressure, using a rotary evaporator (Buchi R-110 Rotavapor, Switzerland) at $150 \mathrm{rpm}$. The nanosystems were left to mature overnight at $4^{\circ} \mathrm{C}$. For sterility, all the above mentioned steps were done under aseptic conditions. All glassware was sterilized by autoclaving, phosphate buffered saline was passed through a $0.22 \mu \mathrm{m}$ membrane filter, and the entire procedure was carried out in a laminar flow hood (Esco, Singapore).

\subsection{Size and Zeta Potential Measurements}

The size and surface charge were determined by light scattering based on laser diffraction ${ }^{47}$ using the Malvern Zeta sizer Nano ZS (Malvern Instruments Ltd., Worcestershire, UK). The measurements were performed using a $45 \mathrm{~mm}$ focus objective and a beam length of 2.4 $\mathrm{mm}$. All the nanosystems were diluted 1:200, 1:100, 1:50, 1:25 and 1:10 with phosphate buffer for size and zeta potential measurements, respectively to observe the dilution effect. For this purpose, the samples were diluted to appropriate concentration. The ZP characterizes the surface charge of dispersed phase and thus gives information about repulsive forces between vesicles and droplets. Absolute higher values than $30 \mathrm{mV}$ usually indicate good stability of the system. Also, the size and ZP values were measured with time over 5 weeks during storage at room temperature.

\subsection{Entrapment Efficiency}

The entrapped diclofenac sodium in the nanosystems was separated from the unentrapped by centrifugation. At predetermined time intervals $0.25 \mathrm{~mL}$ of the dispersion was withdrawn and the aliquot was centrifuged (Eppendorf centrifuge, Eppendorf, Germany) at 14,000 $\times g$ for $30 \mathrm{~min}$, and the supernatant was analysed using UV spectrophotometer. All experiments were conducted in triplicate. The entrapment efficiency was calculated according to the following equation ${ }^{48}$ :

Entrapment efficiency $(\%)=\{$ Amt of DFS entrapped $/$ Total amount of DFS $\} \times 100$

\subsection{In-vitro Release of DFS from nanosystems}

The release of DFS from nanosystems was determined using the membrane diffusion technique $e^{49-51}$. An accurately measured amount of DFS nanosystems, equivalent to $1 \mathrm{mg}$ drug or a volume of $0.5 \mathrm{~mL}$ of preparation was placed in a dialysis bag ( $3.8 \mathrm{~cm}$ in length). Dialysis tubing consisted of regenerated cellulose, a material chemically and physically treated to increase its resistance (MWCO 12,000-14,000 Da, 25-Å pore diameter, Himedia, India). Both ends were tied. The dialysis bag was suspended in $25 \mathrm{~mL}$ PBS at $\mathrm{pH} 7.4$ and maintained at $37 \pm 0.5^{\circ} \mathrm{C}$. The dispersion was rotated at 200 rpm on a magnetic stirrer (REMI, India). At predetermined time intervals of $0.5,1,2,3,4,6,8$ and $12 \mathrm{hrs}, 1 \mathrm{~mL}$ aliquots were sampled and replaced with $1 \mathrm{~mL}$ fresh $\mathrm{pH}$ 7.4 PBS, which was maintained at $37 \pm 0.5^{\circ} \mathrm{C}$. Drug concentrations were quantified using UV spectrophotometer at $276 \mathrm{~nm}$, and all experiments were conducted in triplicate.

Table 3. Composition of diclofenac sodium nanosystems

\begin{tabular}{|c|c|}
\hline Code & Composition \\
\hline LIP001 & LC+CH+SD+T8=1:1:2:3 \\
\hline NIO002 & $\mathrm{S} 6+\mathrm{CH}+\mathrm{T} 8=2: 3: 1$ \\
\hline NANOE003 & $\mathrm{O}+\mathrm{T} 8+\mathrm{LC}+\mathrm{P} 2=2: 1: 1$ \\
\hline
\end{tabular}

LC:Soya lecithin; CH:Cholesterol; T8:polysorbate 80; DFS:Diclofenac sodium; SD:sodium deoxycholate; S6:span 60; O:oil, P2:polysorbate 20

\section{Results and Discussion}

\section{Size Analysis of nanosystems}

Table 4.0 shows the results of size measurement. As evident from table 1 , the size of nanosystems was not much significantly different with negative zetapotential. The formation of stable liposomes can be attributed to the inclusion of charge inducer which increases the spacing between the adjacent layers due to repulsion forces, resulting in the formation of stable liposomes ${ }^{52}$. Furthermore, the charged lecithin electrostatically attracts the DS counterion, which may be expected to push phospholipids lead groups apart, hence increasing the size ${ }^{53}$. The mechanism of niosome formation ${ }^{54}$ is from splicing of two monolayers of inverted micelles collapsing to each other and hence more easily curved, which lead to a decrease in the size. In most typical processes nanoemulsions are formed from an aqueous surfactant solution aggregating into micelles. In the course of the water dilution process of the condensed reverse micelles (concentrates), a bicontinuous phase, consisting of long 
domains, inverts into $\mathrm{O} / \mathrm{W}$ droplets and eventually the structures turn into oil nano-droplets dispersed in a water continuous phase. The two major processes of nucleation and growth are inverted. The large domains of the $\mathrm{O} / \mathrm{W}$ droplets (obtained from the bicontinuous phase) slowly shrink (by a chopping process and edge termination) but in parallel, many of the reformed droplets re-assemble (coalesce) into larger droplets above $60 \mathrm{wt} \%$ water content. These results are well correlated to the results obtained by de Campo et al., $2004^{55}$. Our results are in good agreement with the results of Ko et al., $2003^{56}$, who studied a nonionic $\mathrm{O} / \mathrm{W}$ microemulsion system containing $\mathrm{C} 18: 1 \mathrm{E} 10$ as surfactant, MCT and retinyl palmitate $(1: 1 \mathrm{w} / \mathrm{w})$ as the oil phase and water. They calculated the $\mathrm{O} / \mathrm{W}$ droplet size from the diffusion coefficients obtained from PGSE-NMR measurements. They found that upon increasing the oil phase concentration at the expense of the water concentration (from 1 to 7 wt.\%) while keeping the surfactant concentration fixed, the droplet size increased which correlates with our hypothesis that oil increases the size of the droplet. The average droplet size is not affected by the presence of PC molecules in the surfactant mixture Araya et al., $2005^{57}$. The droplets in the empty system are larger than in the loaded ones, but the trend is similar. Thus, the presence of diclofenac sodium increases the restructuring effect of the droplets upon dilution, thus smaller droplets are detected. The results also suggest that diclofenac sodium is solubilized at the interface of the $\mathrm{O} / \mathrm{W}$ droplets. The mean globule size depended on the concentration of polysorbate 80 and was strongly influenced by the presence of lecithin. The addition of PS increased the globule size. The higher the PS content, the higher the globule size of the nanoemulsion. As shown in Fig 1, the mean size of the systems was decreased upon increasing dilution. Among all the systems, the mean size of niosomes was least which was decreased to $204 \mathrm{~nm}$ upon increasing the dilution upto 1:200. Fig 2 depicts the dilution effect on the impact of charge i.e; negative zeta potential of the nanosystems. On similar lines with size, the zeta potantial also decreased with increasing dilution as shown in Fig 2 . The ZP changes followed the same pattern in all the nanosystems at higher dilutions. The stability assessments of the formulations were tested as change in results with respect to time. Zeta potential reduction was observed in all carrier systems with increase in dilution. Among these, niosomes had shown a significant decrease in negative zeta potential. The reduction in zeta potential of niosomes was possibly due to the change surfactant adsorption.

Table 4. Characterization of diclofenac sodium nanosystems

\begin{tabular}{|c|c|c|c|}
\hline Code & Size (nm) & $\begin{array}{c}\text { Zetapotential } \\
(\mathrm{mv})\end{array}$ & $\begin{array}{c}\text { Encapsulation } \\
(\%)\end{array}$ \\
\hline LIP001 & $201 \pm 5.4$ & $-14.3 \pm 0.3$ & 75 \\
\hline NIO002 & $212 \pm 4.6$ & $-9.32 \pm 0.2$ & 82 \\
\hline NANOE003 & $204 \pm 3.5$ & $-11.8 \pm 0.5$ & 78 \\
\hline
\end{tabular}

LC:Soya lecithin; CH:Cholesterol; T8:polysorbate 80; DFS:Diclofenac sodium; SD:sodium deoxycholate; S6:span 60; O:oil, P2:polysorbate 20

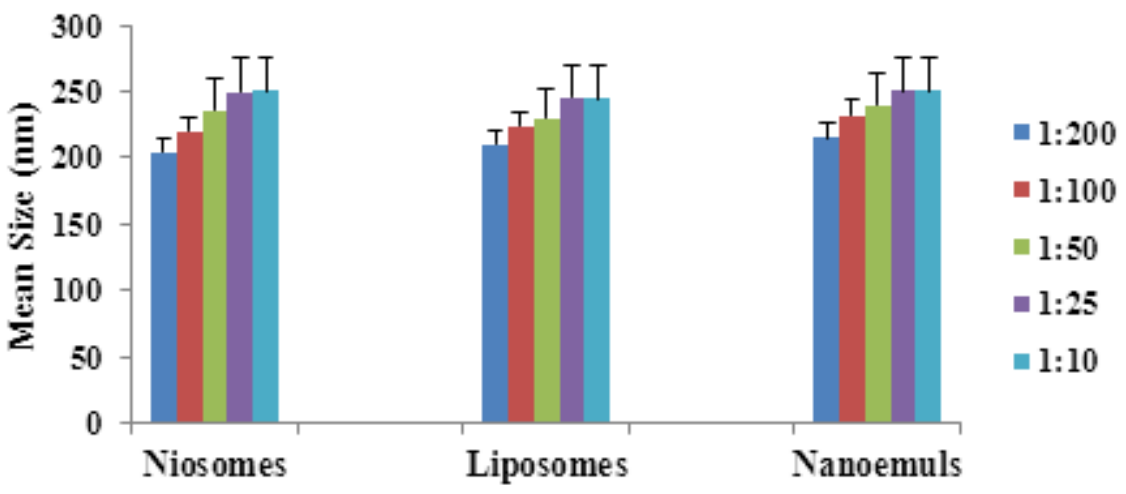

Figure 1. Dilution effect of liposomes, niosomes and nanoemulsion on size

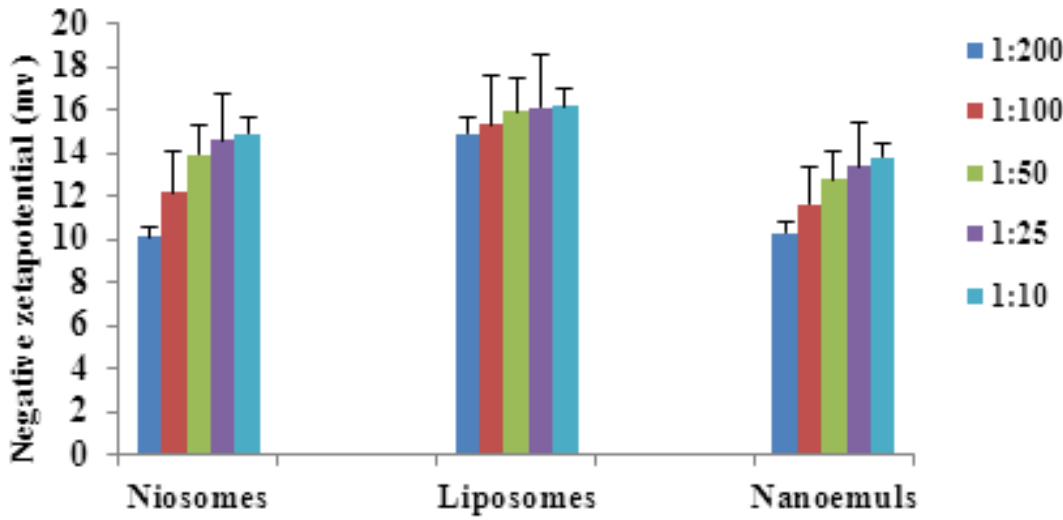

Figure 2.. Dilution effect of liposomes, niosomes and nanoemulsion on zeta potential 


\section{Entrapment efficiency}

By inspection of Table 4.0, it is shown that diclofenac sodium encapsulation efficiency varied with the composition and type of nanosystems. The entrapment efficiencies for niosomes prepared were superior to those of nanoemulsion and liposomes. This may be explained by the fact that the vesicles obtained from Span 60 produce higher entrapment efficiencies as the length of alkyl chain is a crucial factor of permeability. Thus, long chain surfactants produce high entrapment ${ }^{58}$. Additionally, the alkyl chain length influences the HLB value of the surfactant which in turn directly influences the drug entrapment efficiency ${ }^{59}$. The lower the HLB of the surfactant the higher will be the drug entrapment efficiency and stability as in the case of niosomes prepared using Span $60(\mathrm{HLB}=4.6)$. Cholesterol is one of the common additives included in the formulation in order to prepare stable niosomes. Cholesterol is known to abolish the gel to lipid phase transition of niosome systems $^{60}$, which could be able to effectively prevent leakage of drug from niosomes ${ }^{61}$, notably the membrane permeability, encapsulation efficiency and bilayer rigidity ${ }^{62}$. Charged oil is often used to prevent globule aggregation and increase the stability of nnanoemulsion thus was found to have more entrapment than liposomes ${ }^{63}$. Also, the concerning the effect of nanosystem on the encapsulation efficiency of diclofenac sodium, results showed that the $\mathrm{EE} \%$ had higher values in the case of niosomes than in liposomes. This finding may be because niosomes were prepared at $\mathrm{pH} 7.4$ and DFS has $\mathrm{pH}$ dependent solubility and it has minimum solubility at this $\mathrm{pH}$. This will increase the unionized fraction of DFS, which is lipophilic in nature $^{64}$. Due to the fact that MLVs contain multiple lamellae capable of loading a higher mass of lipophilic drug than $\mathrm{ULVs}^{65}, \mathrm{EE} \%$ had higher values in the case of niosomes than liposomes. Concerning the effect of type of surfactants on $\mathrm{EE} \%$, results showed that the $\mathrm{EE} \%$ had higher values in the case of nanoemulsion than liposomes. This result may be because the encapsulation of DFS depends on the fluidity of the phospholipids bilayer ${ }^{66}$. The increase in EE\% by increasing P2 content occur because by increasing the $\mathrm{P} 2$ concentration, resulting in higher stability and reduced permeability of the oil $^{67}$ and hence greater drug retention ${ }^{68}$. Decreasing $\mathrm{EE} \%$ with increasing $\mathrm{CH}$ ratio above a certain limit may be due to the fact that increasing $\mathrm{CH}$ above certain concentration can disrupt the regular linear structure of liposomal membrane ${ }^{69}$. Concerning the effect of dilution and effect of time on the entrapment of DFS in nanosystems, results showed increase in dilution decreased entrapment proportionately in all the nanosystems (Fig 3, 4 and 5) and with time decrease in entrapment (Fig 6,7 and 8). This behavior could be due to increase in size of nanosystems, thus causing leakage of the drug.

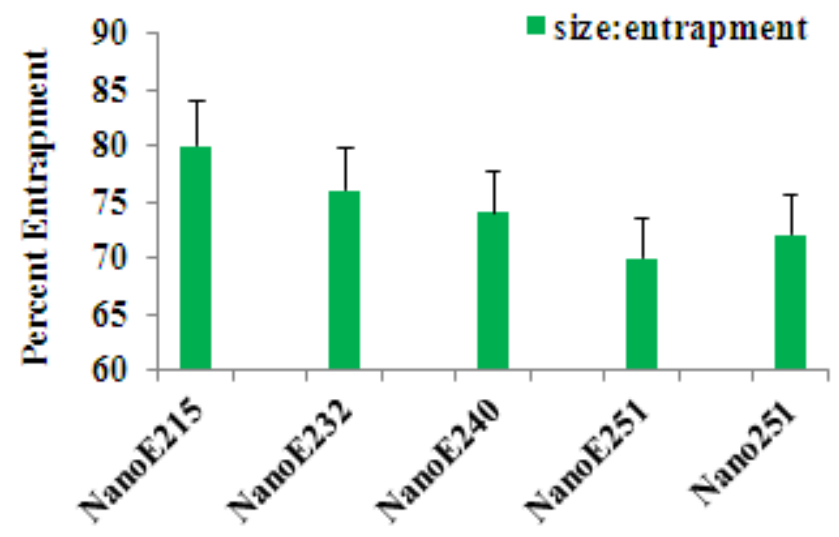

Figure 3. Dilution effect on entrapment of diclofenac sodium in nanoemulsions $(1: 200,1: 100,1: 50,1: 25,1: 10)$

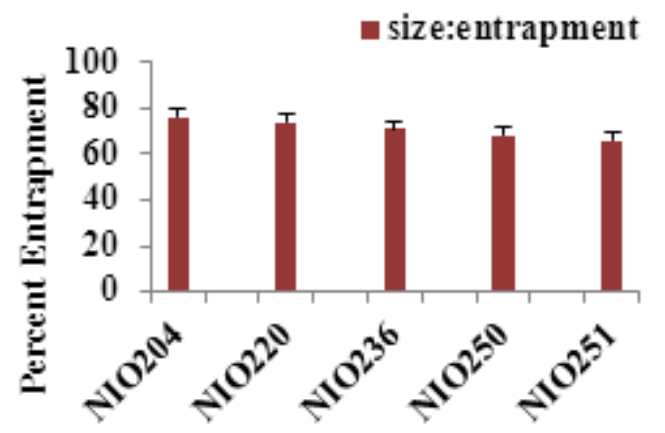

Figure 4. Dilution effect on entrapment of diclofenac sodium in niosomes

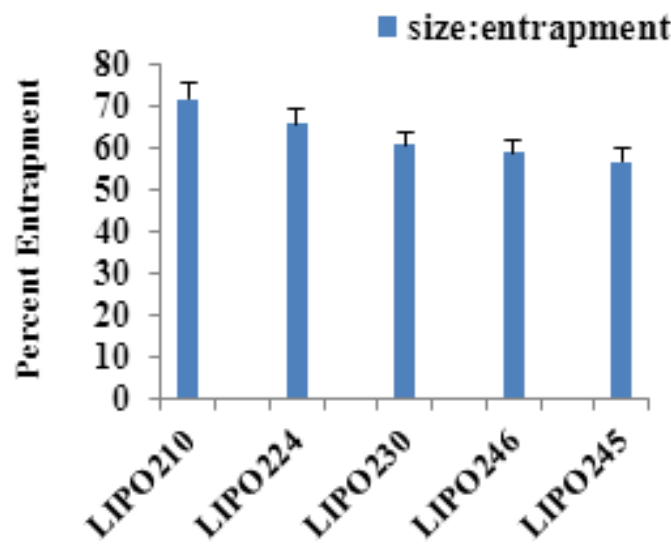

Figure 5. Dilution effect on entrapment of diclofenac sodium in liposomes

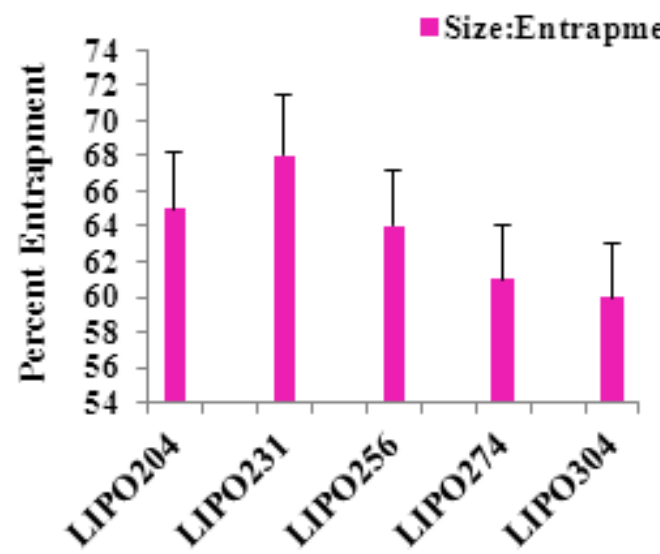

Figure 6. Effect of time on the entrapment of diclofenac sodium from liposomes ( 5 weeks, 4 weeks, 3 weeks, 2 weeks and 1 week) 


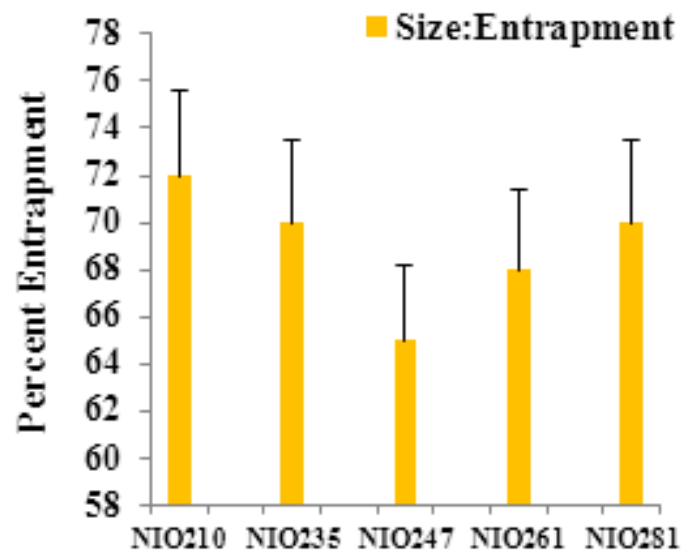

Figure 7. Effect of time on the entrapment of diclofenac sodium from niosomes (5 weeks, 4 weeks, 3 weeks, 2 weeks and 1 week)

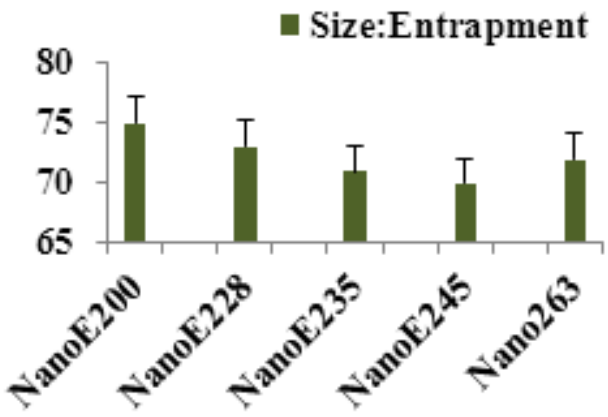

Figure 8. Effect of time on the entrapment of diclofenac sodium from nanoemulsions ( 5 weeks, 4 weeks, 3 weeks, 2 weeks and 1 week)

\section{In Vitro Release Studies}

Results of in-vitro studies on the release of diclofenac sodium nanosystems prepared using lipids, surfactants and cosolvents are shown in Figs. 9 respectively. The percentage of drug released with the effect of dilution and time from the nanosystems are shown in Fig 10 to 15 respectively. Nano formulations showed slower release rate than diclofenac sodium solution. Significant changes in release were observed upon changing the composition used in the nanosystems. By inspection of the data, it could be concluded and can be explained by the fact that niosomes exhibit an alkyl chain length-dependent release and the higher the chain length, the lower the release rate ${ }^{70}$. It is clear that the release is retarded in presence of lecithin in liposome, span 60 in niosome and oil in nanoemulsion. This confirms that the components stabilize the structure of outer membrane and renders them less permeable ${ }^{71}$. From the results, it is obvious that the increase of cholesterol markedly reduced the efflux of the drug from vesicular preparations (Fig 9), which is in accordance with its membrane stabilizing ability ${ }^{72}$. Cholesterol is known to abolish the gel to liquid phase transition of niosome systems $^{73}$, resulting in vesicular that are less leaky ${ }^{74}$. Therefore, the diffusion of DFS entrapped in the hydrophobic regions of the vesicles would be expected to occur over a prolonged period of time. On the contrary to previous results, the increase of cholesterol time slightly increased the efflux of the drug from nanosystems. The release profiles of DFS from nanosystems reveal that the presence of structured components in the nanosystems stabilizes the bilayers and decreases their permeability. However, contrary to previous results, increase in time gradually reduces the permeability. Therefore, it is to be noted that the in vitro release results are consistent with those of the entrapment efficiency. Thus, the comparitive release data indicate that, by encapsulation of drug into nanosystems, it is possible to sustain and control the release of the drug for a longer duration ${ }^{75}$. The invitro release of the systems was also affected with increase in time. Fig 13, 14 and 15 shows the changes in release profile with time. In Fig $13,75 \%$ release was observed from niosomes after 1 week. But it was decreased to $59 \%$ after 5 weeks of time period. Similarly as shown in Fig 14 and 15 from liposomes and nano emulsion, the release was decreased from $65 \%$ to $60 \%$ and $75 \%$ to $70 \%$ respectively. Thus, he release profiles obtained were almost similar in all the formulations as shown in Fig 9. It is found that $85 \%$ of diclofenac sodium diffused out from the colloidal systems within $8 \mathrm{hrs}$ and practically all the drug was released within $12 \mathrm{hrs}$. In addition to this controlled release, the similarity of the release profiles obtained for liposomes, niosomes and nanoemulsion evidences that the internal structure has little role in the release process. Consequently, it can be established that the release of diclofenac sodium from the colloidal carriers is solely affected by the partition of the drug between the oily droplets/vesicles and the external aqueous medium. This release mechanism was also corroborated by the fact that the main factor controlling the release of diclofenac sodium is the volume of the aqueous medium. This was explained by the dilution effect as shown in Fig 10,11 and 12. The drug releases fast and completely from the nanocarriers upon high dilution, but it is slowed down a little when they are not diluted. In Fig 10 and Fig 12, maximum amount of diclofenac sodium was released from nanoemulsion as well as liposome after $12 \mathrm{hrs}$ at 1 in 200 dilution where as in niosomes (Fig 11) it was found at 1 in 100 dilution. But surprisingly, the release was decreased upon further dilution. The major mechanism for drug release was partitioning of drug from carrier as a result of changes in phase volume ratio. Fig 13, 14 and 15 states the effect of time on release profiles of diclofenac sodium with respect to size.

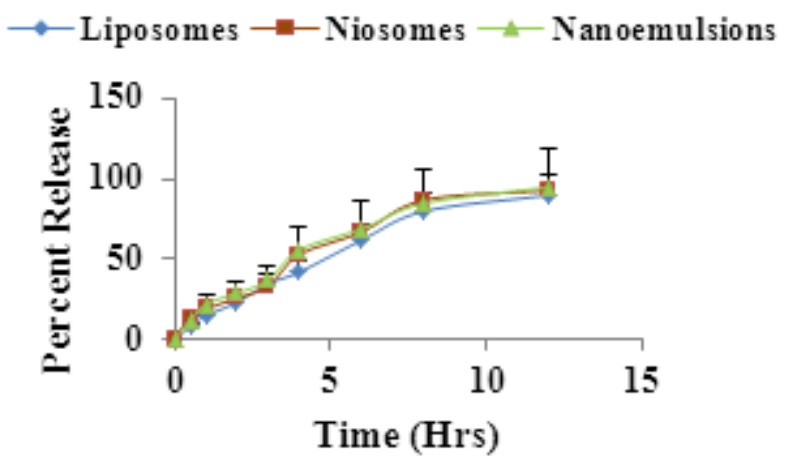

Figure 9. Release profiles of diclofenac sodium liposomes, niosomes and nanoemulsion in phosphate buffer 


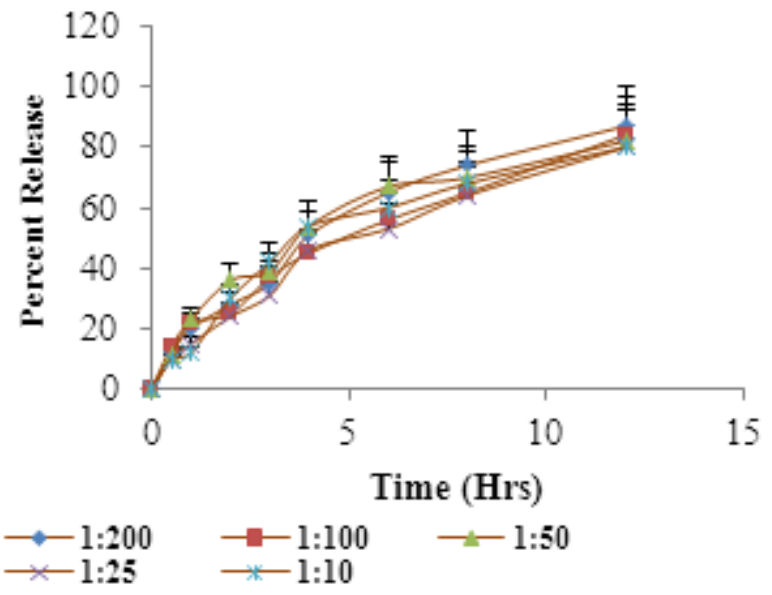

Figure 10. Dilution effect on release profile of diclofenac sodium from nanoemulsions

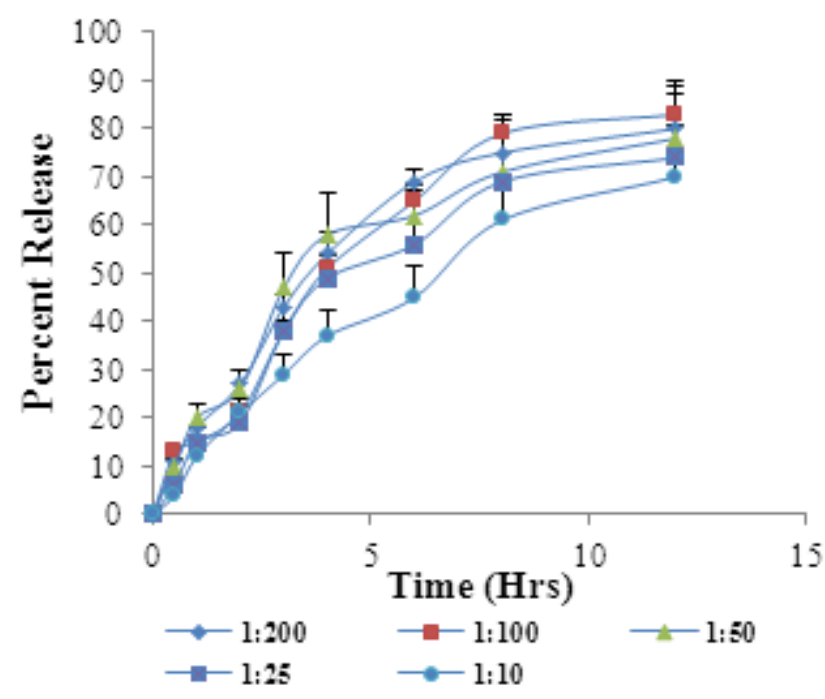

Figure 11. Dilution effect on release profile of diclofenac sodium from Niosomes

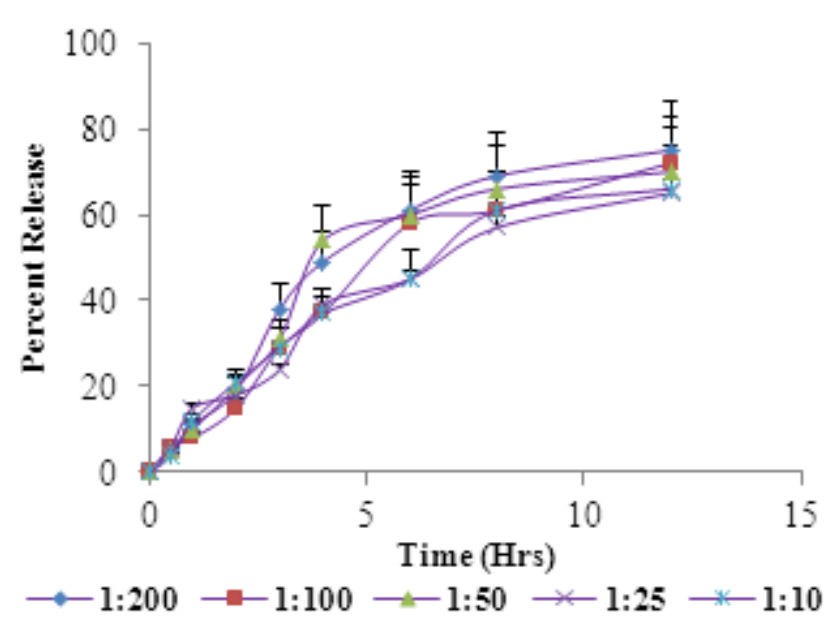

Figure 12. Dilution effect on release profile of diclofenac sodium from Liposomes

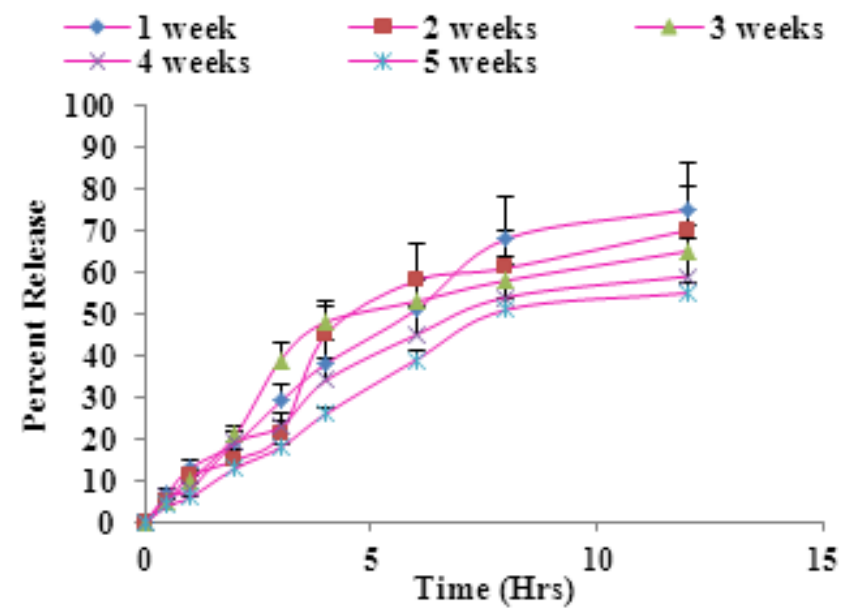

Figure 13. Effect of time on the release profile of diclofenac sodium from niosomes

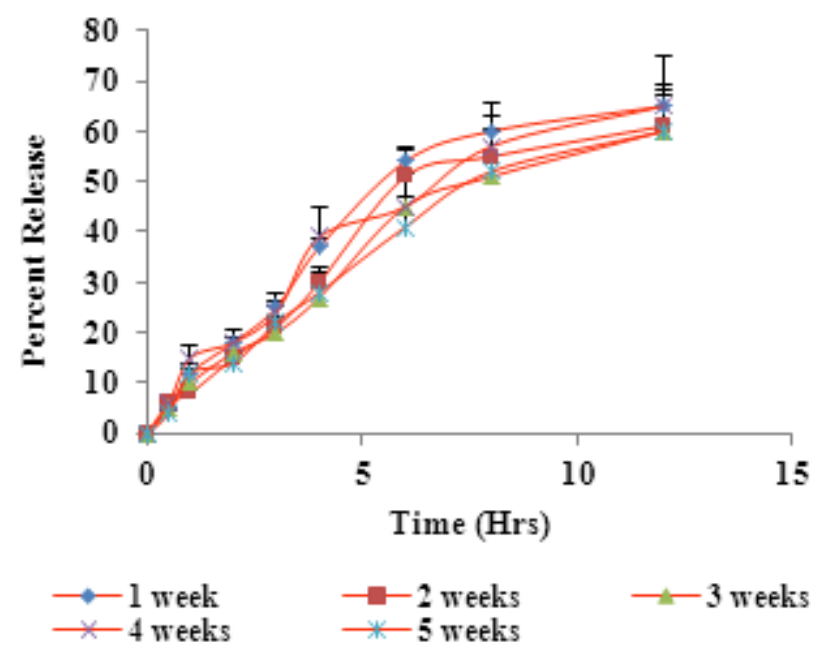

Figure 14. Effect of time on the release profile of diclofenac sodium from liposomes

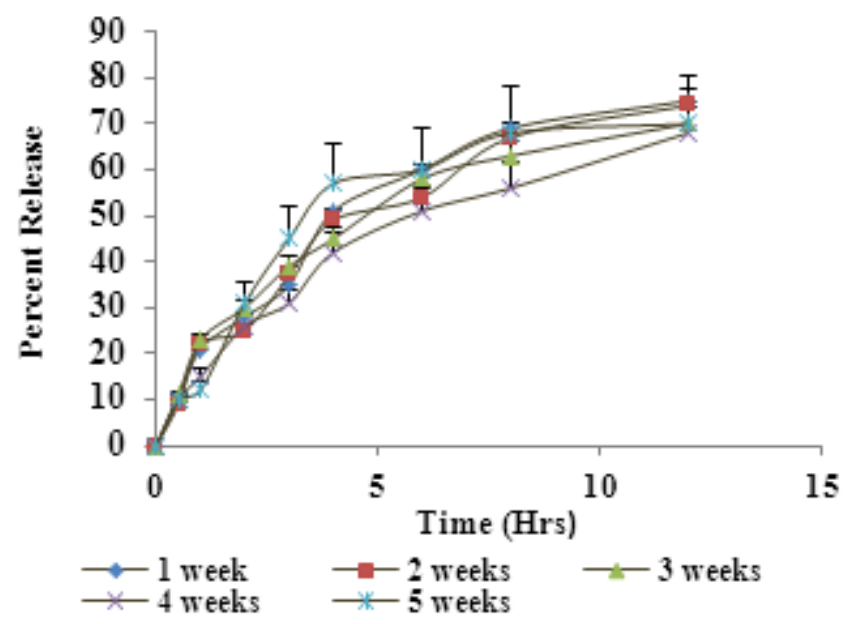

Figure 15. Effect of time on the release profile of diclofenac sodium from nanoemulsions 


\section{Conclusions}

This work describes the development of nanosystems of diclofenac sodium. The interest of these diclofenac sodium loaded nanosystems was evidenced by the fact that they significantly controlled the release of diclofenac sodium. These nanosystems released their drug content rapidly upon dilution. The similar behavior of the three systems indicates that the colloidal nature of the systems is the key factor responsible for their positive behavior. In conclusion, the results of this study emphasize the potential of liposomes, niosomes and nanoemulsions as promising future nanosystems for diclofenac sodium. The results of this study show that cholesterol content, type of surfactant and the presence of charge altered the entrapment efficiency and release rate of DFS from nanosystems.

\section{REFERENCES}

[1] Gregoriadis, G. (1976) The carrier potential of liposomes in biology and medicine. N. Engl.J. Med. 295,704-710.

[2] Grimaldi, S., Lisi, A., Pozzi,D. a and Santoro, N.(1997) Attempts to use liposomes and RBS ghosts as vectors in drug and antisense therapy of virus infection. Res. Virol. 148, 177-180.

[3] M. S. Mufamadi, V. Pillay, Y. E. Choonara et al., "A review on composite liposomal technologies for specialized drug delivery," Journal of Drug Delivery, pp. 2-19, 2011

[4] Gregoriadis, G. (1989) Liposomes as carriers of drugs. Observations on vesicle fate after injection and its control. Subcell. Biochem. 14, 363-378.

[5] Gregoriadis, G. and Florence, A.T. (1993) Recent advances in drug target in. Trends. Biotechnol. 11, 440-442.

[6] Ranson, M., Howell, A., Cheeseman, S. and Margison, J. (1996) Liposomal drug delivery. Cancer Treat. Rev. 22, 365-379

[7] Chen, H. and Langer, R. (1997) Magnetically-responsive polymerized liposomes as potential oral delivery vehicles. Pharm. Res. 14, 537-540.

[8] Senior, J. (1987) Fate and behavior of liposomes in vivo: A review of controlling factors. Crit. Rev. Ther. Drug Carrier Syst. 3, 123-193.

[9] Gregoriadis, G. (1989) Liposomes as carries of drugs. Observations on vesicle fate after injection and its control. Subcell. Biochem. 14,363-378.

[10] Hwang, C. (1987) Liposome pharmacokinetics. In: Liposomes: From Biophysics to Therapeutics, (ed.) M. Ostro, New York: Marcel Dekker, pp. 109-156.

[11] Gregoriadis, G. (1988) Fate of injected liposomes; Observations on entrapped solute retention, vesicle clearance and tissue distribution in vivo. In: Liposomes as Drug Carriers: Recent Trends and progress, (ed.). G. Gregoriadis, John Wiley and Sons Ltd. New York: Marcel Dekker, 3-18

[12] Uchegbu, I.F., Vyas, S.P., 1998. Non-ionic surfactant based vesicles (niosomes) in drug delivery. Int. J. Pharm. 172, 3370.

[13] Uchegbu, I.F., Florence, A.T., 1995. Non-ionic surfactant vesicles (niosomes): physical and pharmaceutical chemistry. Adv. Colloid Interface Sci. 58, 1-55.

[14] van Hal, D., Bouwstra, J.A., Junginger, H.E., 1992. Preparation and characterization of new dermal dosage form for antipsoriatic drug dithranol, based on non-ionic surfactant vesicles. Eur. J. Pharm. Biopharm. 38, 47s.

[15] Echoyen, L.E., Hernandez, J.C., Kaifer, A.E., Gokel, G.W., Echoyen, L., 1988. Aggregates of steroidal lariat ethers: the first example of non-ionic liposomes (niosomes) formed from neutral crown ethers compounds. J. Chem. Soc., Chem. Comm. 8, 836-837.

[16] Hofland, H.E.J., Bouwstra, J.A., Ponec, M., Bodde, H.E., Spies, F., Verhoef, J.C., Junginger, H.E., 1991. Interactions of non-ionic surfactant vesicles with cultured kertinocytes and human skin in vitro: a survey of toxicological aspects and ultrastrucural changes in stratum corneum. J. Control Release $16,155-168$.

[17] Tadros, T.F., Izquierdo, P., Esquena, J., Solans, C., 2004. Formation and stability of nano- emulsions. Adv. Colloid Interface Sci. 108-109, 303-318.

[18] Gallarate, M., Carlotti, M.E., Trotta, M., Bovo, S., 1999. On the stability of ascorbic acid in emulsified systems for topical and cosmetic use. Int. J. Pharm. 188, 233-241.

[19] Er Ãfnofas, I., Csoka, I., Csany, E., Orosz, K., Makai, M., 1998. Proceedings of 2nd World Meeting APGI/APV, Paris, pp. 805-806.

[20] Fukushima, S., Kishimoto, S., Takeuchi, Y., Fukushima, M., 2000. Preparation and evaluation of $\mathrm{o} / \mathrm{w}$ type emulsions containing antitumor prostaglandin. Adv. Drug Deliv. Rev. $45,65-75$.

[21] Asiyanbola B, Soboyejo W. For the surgeon: an introduction to nanotechnology. J Surg Educ 2008; 65:155-61

[22] Torchilin P. Multifunctional nanocarriers. Advanced Drug Delivery Reviews, 2006, 58:1532- 1555

[23] Joshi, M. \& Patravale, V. (2008). Nanostructured lipid carrier based gel of celecoxib. Int J Pharm, 346:124-132.

[24] Luengo J.; Weiss, B., Schneider, M., Ehlers, A. \& Stracke, F. et al. (2006). Influence of nanoencapsulation on human skin transport of flufenamic acid. Skin Pharmacol Physiol, Vol. 19(4):190-197.

[25] Gonzalez-Mira E.; Nikolic, S., Garcia, ML., Egea, MA. \&Souto EB., et al. (2011). Potential use of nanostructured lipid carriers for dermal delivery of flurbiprofen. J Pharm Sci, Vol. 100, 242-251.

[26] Jain, SK.; Chourasia, MK., Masuriha, R., Soni, V. \& Jain, A. et al. (2005). Solid lipid nanoparticles bearing flurbiprofen for transdermal delivery. Drug Deliv, Vol. 12, No. 4, 207-215.

[27] Ricci, M.; Puglia, C., Bonina, F., Di Giovanni, C., Giovagnoli, S \& Rossi, C. (2005). Evaluation of indomethacin percutaneous absorption from nanostructured lipid carriers (NLC): in vitro and in vivo studies. J Pharm Sci, Vol. 94, No. 5, pp. 1149-1159.

[28] Miyazaki S.; Takahashi, A., Kubo, W., Bachynsky, J. \& 
Löebenberg, R. (2003). Poly nbutylcyanoacrylate (PNBCA) nanocapsules as a carrier for NSAIDs: in vitro release and in vivo skin penetration. J Pharm Pharm Sci, Vol. 6, No. 2, pp. $238-245$.

[29] Puglia, C.; Blasi, P., Rizza, L., Schoubben, A., Bonina, F. et al. (2008). Lipid nanoparticles for prolonged dermal delivery: an in vitro and in vivo investigation. Int J Pharm, Vol. 357, No. $1-2,295-304$

[30] Puglia C.; Filosa, R., Peduto, A., de Caprariis, P. \& Rizza, L. et al. (2006). Evaluation of alternative strategies to optimize ketorolac transdermal delivery. AAPS PharmSciTech, Vol. 7, No. 3, pp. E1.

[31] Alves, PM.; Pohlmann, AR. \& Guterres, SS. (2005). Semisolid dermal formulations containing nimesulide-loaded nanocapsules, nanospheres or nanoemulsion: development and rheological characterization. Pharmazie, Vol. 60, No.12, pp. $900-904$.

[32] P.P. Tirumalasetty, J.G. Eley, Permeability enhancing effects of the alkylglycoside, octylglucoside, on insulin permeation across epithelial membrane in vitro, J. Pharm. Pharm. Sci. 9 (1) (2006) 32-39.

[33] J. Risbo, K. Jorgensen, M.M. Sperotto, O.G. Mouritsen, Phase behavior and permeability properties of phospholipid bilayers containing a short chain phospholipid permeability enhancer, Biochim. Biophys. Acta- Biomembr. 1329 (1) (1997) 85-96.

[34] M. Kirjavainen, A. Urtti, J. Mönkkönen, J. Hirvonen, Influence of lipids on the mannitol flux during transdermal iontophoresis in vitro, Eur. J. Pharma. Sci. 10 (2) (2000) 97102.

[35] D.Z. Liu, E.L. LeCluyse, D.R. Thakker, Dodecylphosphocholine-mediated enhancement of paracellular permeability and cytotoxicity in Caco-2 cell monolayers, J. Pharm. Sci. 88 (11) (1999) 1161-1168.

[36] D.Z. Liu, S.L. Morris-Natschke, L.S. Kucera, K.S. Ishaq, D.R. Thakker, Structure-activity relationships for enhancement of paracellular permeability by 2-alkoxy-3-alkylamidopropylphosphocholines across Caco-2 cell monolayers, J. Pharm. Sci. 88 (11) (1999) 1169-1174.

[37] Gulten Kantarc1,Isik Ozguney,H. Yeșim Karasulu,Sevgi Arzık, and Tamer Guneri, AAPS PharmSciTech(2007); 8 (4): E1-E7

[38] Saeed Ghanbarzadeh, Sanam Aramil. Enhanced Transdermal Delivery of Diclofenac Sodium via Conventional Liposomes, Ethosomes, and Transfersomes BioMed Research International (2013); 7: 1-8

[39] Aviram Spernath, Abraham Aserin, Lior Ziserman, Dganit Danino, Nissim Garti, Phosphatidylcholine embedded microemulsions: Physical properties and improved Caco-2 cell permeability Journal of Controlled Release 119 (2007) 279-290

[40] Amnon C. Sintov, Shafir Botner International Journal of Pharmaceutics 311 (2006) 55-62

[41] Muniyandy Saravanan, Kesavan Bhaskar, Gomathinayagam Maharajan, Kalathil Sadasivan Pillai International Journal of Pharmaceutics 283 (2004) 71-82

[42] M. tuncë ay, S. cë alisë, H. S. kasë , M. T. ercan, I. peksoy and A. A. hincal J. microencapsulation, 2000, vol. 17, No. 2,
$145-155$

[43] A. R. kulkarni, K. S. soppimath and T. M. aminabhavi J. microencapsulation, 2000, vol. 17, NO. 4, 449-458

[44] S.K. Mehta, Neeru Bala, Shweta Sharma Colloids and Surfaces A: Physicochem. Eng. Aspects 268 (2005) 90-98

[45] A.J. Baillie, A.T. Florence, L.R. Hume, G.T. Muirhead, A. Rogerson. The preparation and properties of niosomes non-ionic surfactant vesicles. J. Pharm. Pharmacol. 37:863868(1985).

[46] R. Agarwal, O.P. Katare, S.P. Vyas. Preparation and in vitro evaluation of liposomal/niosomal delivery systems for antipsoriatic drug dithranol. Int. J. Pharm. 228:43-52 (2001).

[47] P. Arunothayanun, M.S. Bernard, D.Q.M. Craig, I.F. Uchegbu, A.T. Florence. The effectof processing variables on the physical characteristics of non-ionic surfactant vesicles(niosomes) formed from a hexadecyl diglycerol ether. Int. J. Pharm. 201:7-14 (2000).

[48] K. Ruckmani, B. Jayakar, S.K. Ghosal. Nonionic surfactant vesicles (niosomes) of cytarabine hydrochloride for effective treatment of leukemia: encapsulation, storage and in vitro release. Drug Dev. Ind. Pharm. 26:217-222 (2000).

[49] O.N. El-Gazayerly, and A.H. Hikal. Preparation and evaluation of acetazolamide liposomes as an ocular delivery system. Int. J. Pharm. 158:121-127 (1997).

[50] D. Rambhau. Release studies on niosomes containing fatty alcohols as bilayer stabilizers instead of cholesterol. J. Colloid Interface Sci. 251:360-365 (2002).

[51] M. Glavas-Dodov, K. Goracinova, K.Mladenovska, and E. Fredro- Kumbaradzi. Release profile of lidocaine $\mathrm{HCl}$ from topical liposomal gel formulation. Int. J. Pharm. 242:381384 (2002).

[52] Rania MH, Samar M, Nahed DM, Ahmed SG. Liposomes as an ocular delivery system for acetazolamide: in vitro and in vivo studies. AAPS PharmSciTech. 2007;8(1):1-12.

[53] Gruner SM. Materials properties of liposomal bilayers. In: Ostro MJ, editor. Liposomes from biophysics to therapeutics. New York: Marcel Dekker; 1987. p. 1-38.

[54] U. Olsson, K. Nakamura, H. Kunieda, Normal and reverse vesicles with nonionic surfactant: solvent diffusion and permeability Langmuir 12 (1996) 3045-3054.

[55] L. de Campo, A. Yaghmur, N. Garti, M.E. Leser, B. Folmer, O. Glatter, Five-component food-grade microemulsions: structural characterization by SANS, J. Coll. Interface. Sci. 274 (1) (2004) 251-267.

[56] C.J. Ko, Y.J. Ko, D.M. Kim, H.J. Park, Solution properties and PGSENMR self-diffusion study of C18:1E10/oil/water system, Colloid Surf. A 216 (1-3) (2003) 55-63.

[57] H. Araya, M. Tomita, M. Hayashi, The novel formulation design of $\mathrm{O} / \mathrm{W}$ microemulsion forimproving the gastrointestinal absorption of poorly water soluble compounds, Int. J. Pharm.305 (1-2) (2005) 61-74.

[58] Y. Hao, F. Zhao, N. Li, Y. Yang, and K. Li. Studies on a high encapsulation of colchicine by a niosome system. Int. J. Pharm. 224:73-80 (2002).

[59] R.A. RajaNaresh, G.K. Pillai, N. Udupa, and G. 
Chandrashekar. Anti-inflammatory activity of niosome encapsulated diclofenac sodium in arthritic rats. Indian. J. Pharmacol. 26:46-48 (1994).

[60] C. Cable. An examination of the effects of surface modifications on the physicochemical and biological properties of non-ionic surfactant vesicles. $\mathrm{PhD}$ Thesis. University of Strathclyde, Glasgow, UK (1989).

[61] A. Rogerson, J. Cummings, and A.T. Florence. Adriamycin loaded niosomes-drug entrapment, stability and release. J. Microencap. 4:321-328 (1987).

[62] I.F. Uchegbu, and S.P. Vyas. Non ionic surfactant based vesicles (niosomes) in drug delivery. Int. J. Pharm. 172:3370 (1998)

[63] E. Gianasi, F. Cociancich, I.F. Uchegbu, A.T. Florence, and R. Duncan. Pharmaceutical and biological characterization of a doxorubicin polymer conjugate (PK1) entrapped in sorbitan monostearate Span 60 niosomes. Int. J. Pharm. 148:139-148 (1997).

[64] Claerhout I, Kestelyn Ph, Meire F, Remon J, Decaestecker T, Van Bocxlaer J. Corneal deposits after the topical use of ofloxacin in two children with verna keratoconjunctivitis. Br J Ophthalmol. 2003;87(5):646. doi:10.1136/bjo.87.5.646

[65] Morilla MJ, Benavides P, Lopez MO, Bakas L, Romero EL. Development and in vitro characterization of a benznidazole liposomal formulation. Int J Pharm. 2002;249:89-99. doi:10.1016/ S0378-5173(02)00453-2.

[66] Puglisi G, Fresta M, Mazzone G, Furneri P, Tempera G. Formulation parameters of fluoroquinolone-loaded liposomes and in vitro antimicrobial activity. Int J Pharm. 1995;118:6576. doi:10.1016/0378-5173(94)00340-B.
[67] Perugini P, Pavanetto F. Liposomes containing boronophenylalanine for boron neutron capture therapy. J Microencapsul. 1998;15:473-83. doi:10.3109/02652049809006874

[68] New RRC. Liposomes: a practical approach. Oxford: Oxford University Press; 1990

[69] Gulati M, Grover M, Singh M, Singh S. Study of azathioprine encapsulation into liposomes. J Microencapsul. 1998;15:48594. doi:10.3109/02652049809006875.

[70] G.N. Devaraj, S.R. Parakh, R. Devraj, S.S. Apte, B.R. Rao, and D. Rambhau. Release studies on niosomes containing fatty alcohols as bilayer stabilizers instead of cholesterol. J. Colloid Interface Sci. 251:360-365 (2002).

[71] Y. Hao, F. Zhao, N. Li, Y. Yang, and K. Li. Studies on a high encapsulation of colchicine by a niosome system. Int. J. Pharm. 224:73-80 (2002).

[72] G.V. Betageri, and D.L. Parsons. Drug encapsulation and release from multilamellar and unilamellar liposomes. Int. J. Pharm. 81:235-241 (1992).

[73] C. Cable. An examination of the effects of surface modifications on the physicochemical and biological properties of non-ionic surfactant vesicles. PhD Thesis. University of Strathclyde, Glasgow, UK (1989)

[74] A. Rogerson, J. Cummings, and A.T. Florence. Adriamycin loaded niosomes-drug entrapment, stability and release. J. Microencap. 4:321-328 (1987).

[75] K. Ruckmani, B. Jayakar, and S.K. Ghosal. Nonionic surfactant vesicles (niosomes) of cytarabine hydrochloride for effective treatment of leukemia: encapsulation, storage and in vitro release. Drug Dev. Ind. Pharm. 26:217-222 (2000). 